\title{
Resilience for sustainability as an eco-capability
}

\author{
Ana Augusta Almeida Souza, Marlon Fernandes Rodrigues Alves \\ and Nayele Macini
}

School of Economics, Business Administration and Accounting at Ribeirão Preto, University of São Paulo, São Paulo, Brazil

Luciana Oranges Cezarino

Federal University of Uberlândia, Uberlândia, Brazil, and

Lara Bartocci Liboni

School of Economics, Business Administration and Accounting at Ribeirão Preto, University of São Paulo, São Paulo, Brazil

\begin{abstract}
Purpose - This paper aims to identify the dynamic capabilities that foster organizational resilience towards sustainability.

Design/methodology/approach - The study is a qualitative multi-case study with Brazilian manufacturers of different industries that provides an in-depth exploration of underlying dimensions towards resilience for sustainability.

Findings - The results indicate that to develop organizational resilience towards sustainability, both in theory and in practical terms, the actions required are long-term plans, regular meetings, benchmarking, communication between areas and distinct hierarchies, partnerships and eco-efficient actions. Regarding human aspects, the leader's behaviour and shared culture are the means to encourage, educate and exemplify sustainability for all in the organization.

Research limitations/implications - The study has limitations in the form of a small sample size. The implications indicate a relationship between resilience and dynamic capability for sustainability. In other words, resilience develops organizational, human and technological capabilities for sustainability. Such results can improve the organizational strategy construction methods towards sustainability development.

Practical implications - The study has two practical implications for companies to continue working for sustainability. The first practical implication is the need to work the processes that are aimed at the exchange of information both internally and externally to the organization. It has been seen in managers' speeches that creating ways to listen to employee suggestions could make important resource-saving discoveries and release waste. Another important source of information for improvement of operations is to listen to civil associations and industry and non-governmental organizations, as well as participate in events, lectures and discussion forums. The second practical implication is the need to work with the human side of the organization; sustainability needs to be a part of the worker's daily life, and it needs to become common to them of the need to reflect on how to improve sustainability of processes for which they are responsible. To achieve this goal, companies need to work the pillar of cohesion resilience, emphasizing the behaviour of leaders (role models) and organizational culture.
\end{abstract}

(C) Ana Augusta Almeida Souza, Marlon Fernandes Rodrigues Alves, Nayele Macini, Luciana Oranges Cezarino and Lara Bartocci Liboni. Published by Emerald Publishing Limited. This article is published under the Creative Commons Attribution (CC BY 4.0) licence. Anyone may reproduce, distribute, translate and create derivative works of this article (for both commercial and noncommercial purposes), subject to full attribution to the original publication and authors. The full terms of this licence may be seen at http://creativecommons.org/licences/by/4.0/legalcode
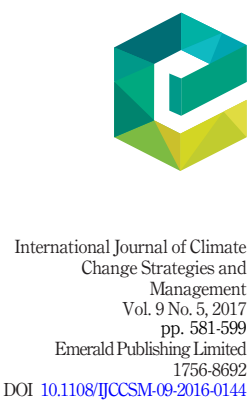


\section{IJCCSM 9,5}

Social implications - The comparative case analysis shows some practices that are able to induce good environment and provide social and organizational benefits, namely, long-term plans, regular meetings, benchmarking, communication between areas and distinct hierarchies, partnerships, eco-efficient actions, behaviour of leaders and shared culture among members of the organization. These practices are the means to encourage, educate and exemplify sustainability for all in the organization.

Originality/value - The originality of this paper is to bring together two streams of the literature, namely, resilience and dynamic capabilities, in the context of sustainability. Drawing on this approach, the study provides a new conceptual model with empirical evidence of key aspects of resilience for sustainability as an eco-capability.

Keywords Sustainability, Brazil, Dynamic Capabilities, Eco-capability, Organizational Resilience

Paper type Research paper

\section{Introduction}

Because humans are dependent on the natural ecosystem and are interested in preserving it, organizations have begun to change owing to external pressures from the government, society and market and internal pressures such as their culture and strategies. Both internal and external sources have been leading organizations towards technologies that lessen their impact on nature, to create environment-friendly products and change its supply chain process (Schrettle et al., 2014).

Sustainable actions seek to meet a unanimous goal, to ensure that the next generation can possess the same resources that an actual society uses today for its development (Munck and Borim-de-Souza, 2009). The way to get there is still under construction. A green action today can be considered different tomorrow owing to new scientific discoveries (Costanza and Patten, 1995).

To keep up with constant updates, companies need to create a permeable organization to deal with new environmental conditions (Lengnick-Hall and Beck, 2005). The dynamic capability theory explains how organizations cope with environmental concerns. That is why dynamic capability is defined as the potential of organizations to deal with stress (Barreto, 2010). Dynamic capability may also be recognized when there is an offering of solutions that creates value for the organization (Eisenhardt and Martin, 2000). Other pieces of literature have viewed dynamic capability to achieve organizational sustainability (Liboni et al., 2015; Liboni et al., 2016). Thus, to maintain their survival and to deal with a constantly changing environment, organizations develop dynamic capabilities, and when it comes to changes in natural resources, eco-capabilities are developed.

Gabler et al. (2015) agreed and recognized some processes and organizational behaviours that facilitate the development of eco-capabilities. These eco-capabilities can positively affect organizational sustainability. As Galpin et al. (2013) stated, sustainability is relevant for organizations, as it affects its performance and can help with survival in a hostile context.

However, maintaining long-term sustainability is a challenge because it requires being able to evaluate and modify the sustainable actions whenever there are perceived changes in social efficiencies, economics and the environment (Fiksel et al., 2014). Therefore, organizations need to develop the ability to constantly adapt their sustainable practices or develop their eco-capabilities.

In this sense, resilience has been used in management literature as a construct that symbolizes the adaptability of organizations. Resilience determines the persistence of relationships within a system and is a measure of the ability of those systems to absorb changes of state variables, driving variables and parameters, and persist (Holling, 1973). This concept carries with it the need for revision and a modification of actions that are 
always under construction; after all, a company must be able to match with its environmental demands (Xu et al., 2015; Lew et al., 2016). Su et al. (2014) stated that resilience is a dynamic capability.

Sustainability and resilience have been studied independently (Derissen et al., 2011; Redman, 2014). For example, Annarelli and Nonino (2016) conducted an exhaustive bibliometric review of organizational resilience and found only one paper to be explicitly connecting both themes (Mari et al., 2014).

The few attempts in this area were conceptual (Derissen et al., 2011; Redman, 2014). For

Sustainability as an ecocapability

example, Fiksel (2003) listed the four pillars that compose resilience for sustainability: adaptability to stimulate organizational learning and multistrategy adaptability to organizational learning; eco-efficiency on natural resources used; and organizational cohesion represented by common shared values. Ortiz-de-Mandojana and Bansal (2016) found an exception to this with the most significant empirical study, in which the authors analyse quantitatively the relationship between social and environmental practices and long-term organizational resilience.

Considering the state of the art of the discussion between sustainability and organizational resilience and the opportunity to draw within the dynamic capabilities framework, the main question of this study is: How is resilience promoted for organizational sustainability? Therefore, the goal is to identify the key dynamic capabilities that foster organizational resilience towards sustainability. For that, past studies used a theory phase consulting followed by a practical phase comparative case analysis on Brazilian industrial companies.

The remainder of this article is continued in Section 2 with a review of: the management theory that supports dynamic capability; the resilience for sustainability that is the accomplishment of the first research phase; and the conceptual model of the paper. Methodological choices are then presented in Section 3. The results and discussion are presented in Section 4. Section 5 concludes with a summary of the research contributions and implications, study limitations and future research directions.

\section{Literature review}

\subsection{Dynamic capability}

Dynamic capability theory arises from the need to explain how companies react to an environment that is constantly changing. This theory attempts to understand how changes in the macro environment interfere with organizational changes and how organizations can keep up with such changes (Augier and Teece, 2008). It aims to provide an understanding of the differences in companies such as the capability to adapt that some have shown and the difficulty of others to adapt (Teece and Pisano, 1994). The support of unique processes and skills by the individuals who are part of the company explains these differences (Augier and Teece, 2009).

Another explanation for differences in the dynamic capabilities is how evolved some process are (Zollo and Winter, 2002). The coevolution of tacit knowledge over experiences, the knowledge shared with employees about the impact of their acts in the organizational competence performance and the codification of knowledge are some indicators of the development of different dynamic capabilities in companies (Zollo and Winter, 2002). According to the authors (Zollo and Winter, 2002), these organizational activities are responsible for developing and adapting processes and routines, allowing the ability to manipulate resources into strategic value creation (Eisenhardt and Martin, 2000).

Strategic value creation is essential in highly competitive times, creating new products, processes, new organizational forms and business models. The consequence of these are the 


\section{IJCCSM 9,5}

implementation of new capabilities to the long-term competitiveness as the maintenance and the ability to conduct a dialogue with employees and customers and the development of the ability to integrate their knowledge in processes, products, services and business strategies (Ayuso et al., 2006).

These capabilities require processes that encourage communication and openness to change in identifying future risks (Ayuso et al., 2006). The management skills to perceive risks, opportunities and other changes that could influence operations are required, and these mainly achieve the realization of changes in routines, decreasing organizational vulnerability (Teece, 2007).

As pressure grows to embrace sustainability, so does the competition to define sustainability and the scope of its embrace (Roper, 2012). Sustainability is an aspect that is part of the organizations' environment, so organizations need to build eco-capabilities to deal with sustainable demands. Features such as the commitment of managers, directors and the president for environmental issues, flexible labour and a shared sense among members about the benefits of sustainable activities are essential for developing ecocapability in human resources (Gabler et al., 2015).

Dynamic capability believes that competitive advantages can be achieved through high organizational process knowledge and the ability to manage resources (Eisenhardt and Martin, 2000). The decision of following sustainability as a strategic value requires the development of capabilities that constantly assess the implemented results and solutions. The dynamic capabilities rise as a potential to solve sustainability problems (Barreto, 2010).

As maintaining long-term sustainability is a critical component for organizations (Fiksel et al., 2014), the sustainable practices need adaptability. Resilience can be a dynamic capability that brings new skills and abilities to help in the sustainability of organizations (Chousa and Castro, 2011). With resilience, companies can renew their organizational practices well in advance (Chousa and Castro, 2011), as the concept allows the monitoring and assimilation of changes before they compromise the organization's future (Fiksel, 2003). Innovating sustainable actions has become a philosophy, and resources are managed to create a favourable environment for organizational adaptations to new environmental conditions that have been imposed (Eisenhardt and Martin, 2000; Lengnick-Hall and Beck, 2005). Figure 1 summarizes and shows the different practices of each kind of dynamic capability.

Figure 1 explores the loop on which the paper theory relies. Dynamic capabilities can be expressed by shared and decoded knowledge that an organization could absorb through constant and past occurrences (Eisenhardt and Martin, 2000; Zollo and Winter, 2002; Ayuso et al., 2006; Teece, 2007). This allows for prevention and attempts to build reliance under different scopes. The indicators can be explicit when an organization presents the ability of holding a dialogue and understands stakeholder needs regarding the business process. In addition, when top executives pursue these capabilities to foster changes, complex adaptation mitigation and, of course, resilience building, occurs. When examining the green area in Figure 1, it is possible to observe the similarity of the actions undertaken by dynamic capabilities and eco-capabilities (Chousa and Castro, 2011; Gabler, Richey and Rapp, 2015). In a way, this possibly affirms that a sustainable context forces an organization to develop capabilities that could make them resilient to future environment.

\subsection{Resilience for environmental sustainability}

Maintaining sustainability management requires constant updating of the means to meet it because there no set of organizational practices that symbolizes the full compliance of sustainability (Winnard et al., 2014). The organization needs to create internal ways to maintain a sustainable path under construction. There are four pillars of organizational 


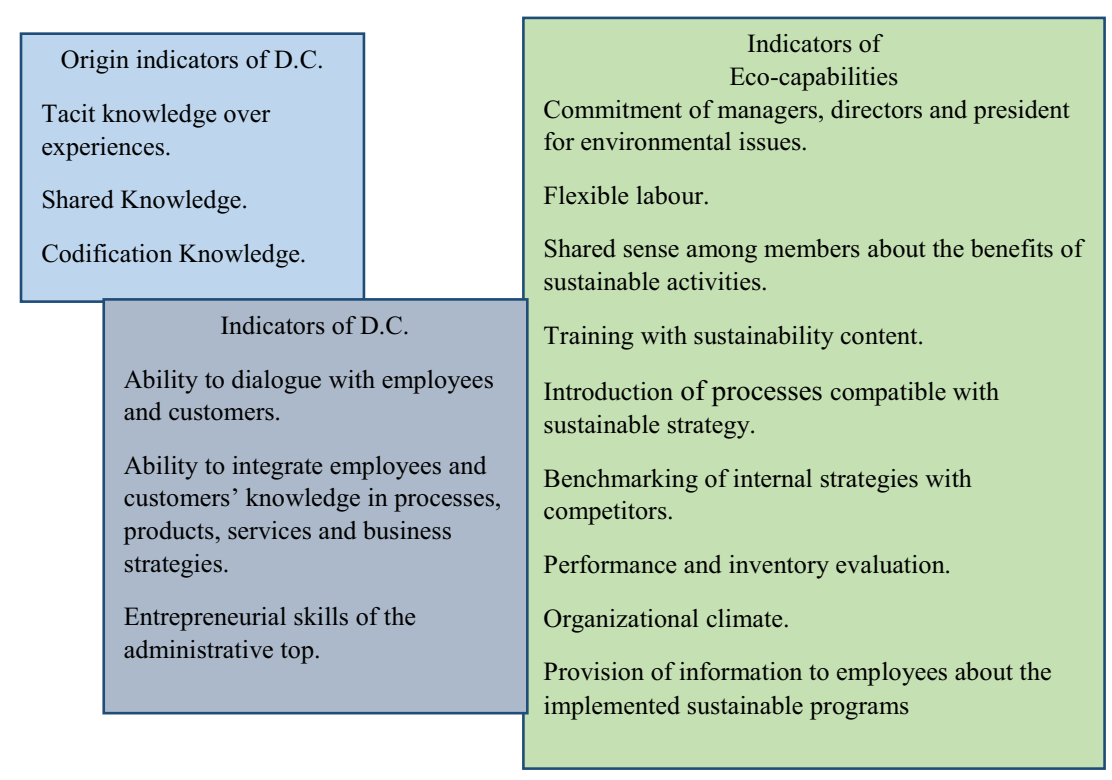

\section{Sustainability as an eco- capability}

585

Figure 1.

Organizational practices that indicate a dynamic capability

resilience for sustainability: diversity strategies, adaptability, cohesion and eco-efficiency (Fiksel, 2003).

The first component of resilience for sustainability comprises the long- and short-term strategies that can be used to circumvent the risks that climate change imposes on the future maintenance of many organizations' activities. The long-term business planning needs to consider climate change that could potentially affect the company (O'Connell and Hou, 2015). For this, companies increase their knowledge of the natural system and develop plans to mitigate threats (Linnenluecke and Griffiths, 2010).

Mirfenderesk and Corkill (2009, p. 157) stated that there are many reasons that require new forms of strategic thinking when dealing with the issue of climate change, such as:

- Predicted changes to the characteristics of the socioeconomic and environmental systems owing to climate change are highly uncertain.

- Climate change happens along with other local, regional and global changes. How to account for these future changes and how they will interact with climate change to produce an impact is a problem that needs to be addressed.

- Some of the social and ecological impacts of climate change-induced flooding cannot be easily measured by monetary terms alone. Therefore, it is difficult to compare these impacts with those that are quantified in terms of monetary value. Finding a common metric for all types of effects remains a problem that needs to be addressed (Mirfenderesk and Corkill, 2009, p. 157).

In addition to the preparation of plans, frequent updates or re-evaluations are necessary to identifying possible improvements in processes (O'Connell and Hou, 2015). Knowing how tasks are performed internally helps senior management to evaluate the strategies implemented because it is real information and it allows seeing the operational gaps that can pose risks to the organization. 


\section{IJCCSM 9,5}

Possessing accurate knowledge of the external reality of the organization also helps avoid surprises in performance. The external reality can be understood through historical accidents caused by companies in the same sector or other sectors to benefit the understanding of current risk reviews (Crichton et al., 2009). Thus, the development of new solutions to problems can be magnified (Juechter et al., 1998).

Adaptability is another component of resilience and involves the ability to learn, decide and act (Bettini et al., 2015). Learning can be developed in a participatory management based on shared decision-making, information sharing, consultation with the various hierarchical levels and sharing authority (divided power) and risks (Galappaththi and Berkes, 2015). The organizational communication becomes an essential tool for the company to be successful in gaining information that can bring solutions to the problem (Bettini et al., 2015).

In this participatory approach, different sources of information can be consulted as essential practice for building resilience (Aldunce et al., 2015) Civil organizations, governments and customers can contribute to the problem solving and revitalization of a business, so there is the need to strengthen relations with various institutions (Aldunce et al., 2015). Working with different networks of those common to the organization increases the variety of experiences that add in building resilience (Aldunce et al., 2015).

This begins the building of the ability to decide what best reflects the new knowledge acquired on shared goals and action plans (Bettini et al., 2015). The ability to act is linked with the creation of new ways for the implementation of the solution. To facilitate this implementation, it is necessary to find support from those involved in the change processes; collaboration increases the chances of a result (Bettini et al., 2015). A resilient business depends on the development of talent inside and outside the organization to generate responses. Thus, alliances and partnerships are critical items, and need to be sustained (McCann et al., 2009).

Cohesion is another component of resilience for there to be sustainability, and it can be understood as something that is shared between people resulting in the formation of a group. Within the organizational environment, managers seek to produce cohesion in his/ her employees in support of organizational objectives and results.

A mean of producing such cohesion is using the organizational culture (Freitas, 1991) in an extremely sophisticated control mechanism, because it seeks to direct the behaviour of its employees with the construction of values, beliefs and convenient conditions for the organization to achieve its results.

The behaviour of leaders is the concrete expression of the organizational culture, and it is how employees learn how they should act. The challenge is to act in the way that directs the behaviour of employees to the values considered most important. It is based on the example set by managers that employees draw what is important to the organization (Schneider et al., 1994).

Cohesion is particularly important to disasters, as they can potentially become the basis for successful models and programmes that can be put into place to be achieved (for instance, disaster resilience). Hence, identifying levels of resilience and cohesion in communities that have experienced disasters has the potential to inform us about the significance of these concepts to disaster preparation and recovery (Townshend et al., 2015). In the same direction, cohesion of thinking and action can build resilience on organizations to promote eco-efficiency, one of the dynamic capabilities towards sustainability.

Eco-efficiency is responsible for incremental innovations to reduce emissions that generate greenhouse gasses; the use of hazardous substances; waste; and the consumption of electricity, water, fossil fuels and raw materials (Aguado et al., 2013). The reduction of negative external effects of production results in the company gaining the approval of society and reducing the costs of its business activity (Chornomaz et al., 2016). In the case of 
climate change, for example, eco-efficiency improvements may come too late to prevent extraordinary ecological, social and environmental dislocations. In the event that global warming (or some unforeseen catastrophe) is inevitable, the only successful strategy will be adaptation, transformation and evolution. To the extent that eco-efficiency investments embitter industrial systems to undermine resilience pathways, they may be counterproductive (Korhonen and Seager, 2008).

Table I summarizes the practices found in the literature review for each pillar.

Sustainability as an ecocapability

\section{Conceptual model}

After revising the dynamic capability and resilience theories, a conceptual model relating the two was made. Gabler et al. (2015) defined which practices, processes and behaviours are necessary to develop capabilities to deal with sustainability demands. Capabilities are especially important. Commitment of managers, directors and the president with sustainability issues is one of the eco-capabilities, and it is related to an indicator of resilience for sustainability. The relation between them is in the cohesion pillar that states the importance of a leader's behaviour as an example for employees (Schneider et al., 1994).

Another capability that also belongs to the cohesion pillar is the organizational climate, which relates to the values and beliefs sustained by the organization. Freitas (1991) believed that organizational culture can model employee behaviour, so the values and beliefs sustained by the company impact human capability to deal with sustainable issues.

According to Gabler et al. (2015), organizational capabilities are composed of three ecocapabilities:

(1) shared sense among members about the benefits of sustainability;

(2) provision of information to employees about the implemented sustainable programmes; and

(3) benchmarking of internal strategies with competitors.

These capabilities match with the adaptability pillar of resilience for sustainability. This pillar is based on the belief in participatory management and in the richness of interactions with stakeholders (employees, clients, suppliers, civil organizations and associations), so communication, sharing and exchanging knowledge are principles of this pillar.

\begin{tabular}{ll}
\hline Four pillars & Organizational practices indicators \\
\hline Diversity of strategies & $\begin{array}{l}\text { Long-term business planning is needed to consider climate change } \\
\text { Developing plans to mitigate threats } \\
\text { Frequent updating or re-evaluation is necessary to identify possible improvements } \\
\text { in processes }\end{array}$ \\
& $\begin{array}{l}\text { Participatory management based on shared decision-making, information sharing, } \\
\text { consulting with various hierarchical levels }\end{array}$ \\
& Working with different networks of those common to the organization \\
& Incorporating new knowledge acquired on shared goals and action plans \\
& Building alliances and partnerships \\
& Organizational sustaining of values and beliefs \\
& Behaviour of leaders expressing the organizational culture \\
Legal compliance & Reducing gasses emissions \\
Ecohesion & Energy saving \\
& Optimizing water use
\end{tabular}

Table I. Organizational practice indicators of resilience for sustainability 
IJCCSM

9,5

\section{8}

Technology capabilities relates to multiple strategies and eco-efficiency. These pillars refer to monitoring, minimizing, mitigating, evaluating and updating sustainable processes, strategies and performances. Figure 2 shows the relations between the concepts from ecocapabilities (dynamic capability theory) and resilience for sustainability (resilience theory).

The model describes the eco-capabilities and the response to each of them is evidence of cohesive thinking and changing. To Fiksel (2006), the current lack of success in improving industrial sustainability coupled with the challenges of biocomplexity and resilience

\section{Eco-capabilities}

\section{Resilience for sustainability}

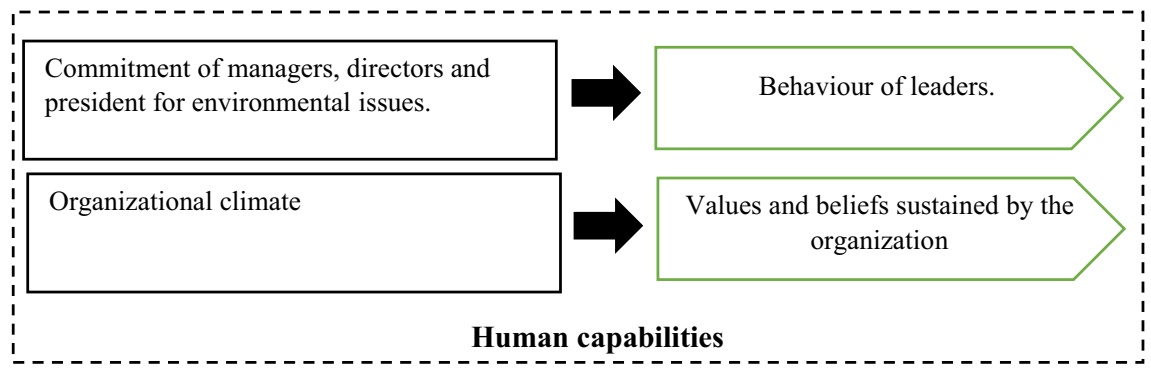

Shared sense among members about the benefits of sustainability and Provision of information to employees about the implemented sustainable programs.

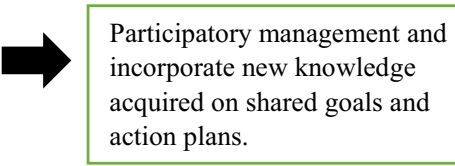

Benchmarking of internal strategies with competitors.

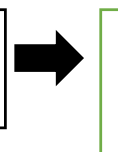

Alliances and partnerships.

\section{Organizational capabilities}

Introduction of processes compatible with sustainable strategy and Performance and inventory evaluation.

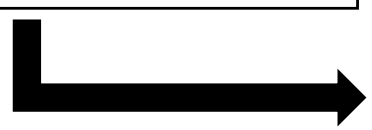

Figure 2.

Conceptual model
Legal compliance;

Reducing gasses emissions;

Energy saving; Optimizing water use; Historical accidents caused by companies in the same sector or

Business planning long-term need to consider climate change;

Develop plans to mitigate threats; Frequent updates or re-evaluation is necessary identifying possible improvements in processes

Technological capabilities other sectors. 
indicates that sustainability is a systems problem requiring collaborative solutions. Only a coordinated global effort, with participation from public, private and nongovernmental organizations, can achieve genuine systemic change.

\section{Method}

\subsection{Research design and cases}

This study adopts the multicase study approach (Table II), which is appropriate when investigating "how" questions related to contemporary issues (Eisenhardt, 1989). The sampling strategy adopts a purposeful selection of a manufacturer's large companies, whereas the dynamic capabilities concepts are more likely the observed ones such as path dependence and routine-based processes (Teece et al., 1997). However, in terms of industry and geographical scope, the study seeks maximum variation, which means that instead of selecting random cases from the population, it chose contrasting cases (Strauss and Corbin, 1998). This allows the study to understand the same phenomenon in distinct environments.

\subsection{Research protocol}

The research protocol represents the general rules respected by the authors to guarantee the study's reliability. The protocol has an overview of the research project and contains field procedures and a script for collecting data and a guide to report the data. These sections were selected based on the study by Yin (2013). The first section (overview) intends to explain the main purpose of the research.

To accomplish the research goal, four interviews with managers of four different enterprises were conducted. The researchers decided to first define who would be the managers. Determined by connections, the researchers chose managers known to them or to other researchers. Second, they made a decision about the necessary resources, such as a computer and a recorder, required for conducting the interviews. The next step was to schedule the interviews according to managers' availability. The two sub-sequential items explain in detail the data collection process and analysis (Langley, 1999) as follows.

4.2.1 Data collection. During the interviews, the interviewer was free to add questions to get the respondent to state what he wanted to know - another typical characteristic of the interview method (Boni and Quaresma, 2005). The semi-structured script was chosen owing to the limited time the interviewees had to collaborate with the research. The script contains closed-ended questions used to characterize the companies where they work, as well as open-ended questions asked by the researcher based on the literature review. All the interviews were recorded with the informants' consent. Because the content of the interviews could be sensitive regarding strategic and environmental issues, the anonymity of the company and the informants have been preserved. The interviews were conducted via Skype to reduce traveling costs. The duration of each interview was $40-60 \mathrm{~min}$. The researcher who conducted the interview was responsible for preparing the transcript in the same week of the interview. Table III shows the questions asked for the respondents.

\begin{tabular}{|c|c|c|c|c|c|}
\hline Characteristics & Company 1 & Company 2 & Company 3 & Company 4 & \\
\hline Size & Large & Large & Large & Large & \\
\hline Sector & Manufacturing & Manufacturing & Manufacturing & Manufacturing & Table II. \\
\hline Geographical scope & National & National & Multinational & Multinational & Characterization of \\
\hline Industry & Chemical & Metallurgical & Agribusiness & Alimentary & companies \\
\hline
\end{tabular}

Sustainability as an ecocapability

589

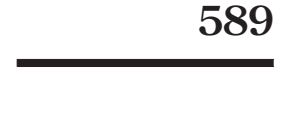




\section{IJCCSM 9,5}

\begin{tabular}{lll} 
Characteristics to evaluate & Questions & Goal \\
\hline Company size & $\begin{array}{l}\text { Microenterprise (up to 19 employees) } \\
\text { Small company (20 to 99 employees) }\end{array}$ & $\begin{array}{l}\text { Characterization of the size of the } \\
\text { company }\end{array}$
\end{tabular}

Efficiency in the use of natural resources
Small company (20 to 99 employees)

Average company (from 100 to 499)

Large company (500 or more)

Reduces emissions of greenhouse gases Optimizes the use of water and energy.

Fulfils legal demands

\section{Open questions}

Questions

Does the company make long-term plans for sustainability? Does the long-term plan include actions to mitigate climate change? Which are the long-term plans?

Are the long-term plans already undergoing updates? How was it done?

Does the organization draw lessons from environmental accidents caused by companies in the same industry or in different industries? How?

Does the company monitor internal projects and operations? How? How often?

Does the company conduct research in partnership with research institutions or universities on changes in sustainability? Does the company carry out joint projects with NGOs, industry

associations in order to achieve sustainability?

What does the company do to increase employees' knowledge of sustainability?

Does the company seek to hear suggestions on the environmental sustainability of its operations? By what channels or actions?

Does the company implement the suggestions? Give an example. Is there discussion about environmental issues between the different hierarchical levels? And among the different sectors of the organization? How does this happen?

Is the organization encouraged to participate in external groups

Table III.

Script of interviews (industry meetings, events) to the organization to improve sources of information on climate change, national policies and environmental management?
Authors

O'Connell and Hou (2015); Crichton et al. (2009); Puente-Rodríguez et al. (2016); Campos (2015); Xu et al.

(2015); Berkes (2009); Plummer and Armitage (2007); Galappaththi and Berkes (2015)

4.2.2 Analysis. All the interviews were transcribed and then analysed and coded. Content analysis technique was used to evaluate the qualitative data (Bardin, 2011), thus aiming to enrich the reading of what was found and explore the content in front of the predefined questions, allowing a reflexive and critical analysis on the subject studied. After interview transcription, the researchers had to link the speeches transcribed with the practices classified into the major categories of diversity of strategies, adaptability, cohesion and ecoefficiency listed in Table I. The next steps are related with organizational, human and technological capabilities. In case the answers did not clearly represent some of the practices listed in the major categories, the researcher had to contact the manager again to clarify the answers to specific questions.

The objective is to connect empirical observations with relevant concepts (Gioia et al., 2013). With central concepts coded, the analysis was advanced for an in-depth understanding 
of relationships. Here, the present study analysis was combined within case and cross-case analyses (Eisenhardt, 1989). That is, the cases were treated as multiple sources for judging similarities and dissimilarities among firms, facilitating the creation of emergent theoretical concepts and their interrelationships (i.e. the basis for an inductive theory).

Sustainability as an ecocapability

\section{Discussion and results}

\subsection{Technological capabilities}

Constructing long-term plans that take climate change into consideration is a resilient action (O'Connell and Hou, 2015). Companies 3 and 4 had long-term plans that were no longer than six years to implement actions to support the preservation of forests and the reforestation of deforested areas: "We made a commitment to halve deforestation in our soybean chain by 2020 and by 2030 end any kind of deforestation in our chain" (speaking of the management 3, 2016).

Company 4 has a current long-term plan for sustainability. According to Manager 4, this plan began in 2010 and has four pillars: packaging, agriculture, water and climate. The packaging pillar refers to two main fronts. The first one is to ensure that used containers are suitable for recycling and are composed of more sustainable materials, the second front is to ensure packaging recycling at the end of its life cycle.

The agriculture pillar is the only one that does not have clear goals to perform, that is why detailed goals for this area began development in 2016. One of the main initiatives for the agriculture pillar is taking care of the most important raw material: milk and milk protein. The project is still at an early stage and its long-term goal is protecting groundwater so that milk suppliers have availability and future quality of water.

The water pillar seeks the preservation of watersheds and ecosystems, especially the basins that the company makes to perform abstraction of water for bottling and marketing. The climate pillar is focused on the emissions issue. Company 4 aims to reduce 50 per cent of its carbon emissions of its entire value chain, reduce 60 per cent of its energy consumption in industrial plants and eliminate its cooling systems' gases containing hydrocarbons. Company 4 aims to achieve all these goals by 2020, as its plan stated in 2010.

Reduction of carbon emissions and the preservation of water sources are the main goals of the long-term plans. Thus, the long-term plans aim is to contribute to the deceleration of climate change. The recent achievement of long-term plans for sustainability suggests that a new drafting process was introduced to enable the sustainability strategy. Thus, the longterm plans for sustainability is a technological capability that contributes to the sustainability of the company (Gabler et al., 2015).

Another resilient action is to update those plans by reviewing their goals. The plans have been recently implemented at Companies 3 and 4 . Therefore, only Company 4 held updates to better define previous goals that were not so detailed. This resilient action is within the technological capability (Gabler et al., 2015). According to the authors, it is part of the ecocapability to use resources to evaluate the performance. Thus, the update is a way to evaluate whether the established plan continues consistently with the preservation needs of the environment for the company and for the world.

As for efficient eco features implemented by the companies, there was great concern for optimizing the use of water and energy, especially the energy savings, as it deals with the emissions factor. These actions are considered eco-efficient and a technological ecocapability. The second biggest concern seen by the discourse with the managers is the fulfilment of legal demands. Some eco-efficient actions are not implemented because of legal reasons. The example comes from Company 4 , which being in the food industry, agreed that the use of recycled packaging in their products may compromise food safety rules set by regulators. Respecting the laws and regulations is eco-efficient. These resources provide 
IJCCSM 9,5

Table IV.

Technological capabilities and resilience actions from companies information to employees about the progress of implemented sustainable processes and help to build technological eco-capability in organizations according to Gabler et al. (2015). Under an active perspective, it seems that these actions generate capabilities that support organizational sustainability continuously through resilience (Table IV).

\subsection{Organizational capabilities}

Participatory management through dialogues with people from the same area or different areas and hierarchies and meetings conducted fortnightly, monthly or quarterly are another ecocapability. All organizations surveyed were open to receiving suggestions for improvements in its operations by their stakeholders. This practice is seen as an organizational capability. Dialogues with stakeholders is an important source to improve sustainability (Gabler et al., 2015).

Manager 1 cites the initiative by the environmental staff to promote a campaign throughout the organization by collecting ideas for improving the organization's sustainability. One of the highlights comes from an employee who suggested to reuse an effluent generated because of the machine lubrication process: "One was the reuse of effluent that we generated in the lubrication of machines process and equipment, buying a filter type, we could reuse the effluent". If the campaign had not been performed, probably the environmental team would not be aware of this reusable option.

Another example from Company 1 was the institutionalization of an internal environmental committee where directors from all areas participate. The committee is responsible for assessing whether the decisions taken are in line with the principles of sustainability. This initiative was a suggestion of Manager 1. The same campaign that made it possible to reuse an effluent generated the committee idea:

Environmental committee that is just made up of people (director of marketing that has to do with sales, industrial director on the operational side, the HR directors, and technical directors that oversees engineering, quality, environment) committee evaluates the decision making geared to sustainability (speaking of Management 1, 2016).

In Company 2, a similar initiative was founded. The environmental staff have promoted a project called "Eyes Open" in which different departments can suggest improvements on various environmental aspects. This programme works as follows: fliers are left in different sectors of the factory so that people can leave their suggestions for environmental improvement. Every day the environmental team collects the filled-out fliers, evaluates the suggestions and thus decides which to implement.

Among the suggestions for improvement achieved by the "Eyes Open" campaign in Company 2, a popular idea that was implemented by Manager 2 was focused on the economy generated by the disposal of chemical containers. Manager 2 described that the production line personnel were given chemicals in small packages. Therefore, they

\begin{tabular}{|c|c|c|c|c|c|c|c|c|}
\hline Companies & $\begin{array}{c}\text { Legal } \\
\text { compliance }\end{array}$ & $\begin{array}{l}\text { Reducing } \\
\text { gases' } \\
\text { emissions }\end{array}$ & $\begin{array}{l}\text { Energy } \\
\text { saving }\end{array}$ & $\begin{array}{l}\text { Optimizing } \\
\text { water use }\end{array}$ & $\begin{array}{l}\text { History of } \\
\text { accidents }\end{array}$ & $\begin{array}{c}\text { Long- } \\
\text { term } \\
\text { planning }\end{array}$ & $\begin{array}{l}\text { Plans to } \\
\text { mitigate } \\
\text { threats }\end{array}$ & $\begin{array}{c}\text { Frequent updates } \\
\text { or re-evaluation } \\
\text { of processes }\end{array}$ \\
\hline Company 1 & $\mathrm{X}$ & $\mathrm{X}$ & $\mathrm{X}$ & $\mathrm{X}$ & - & - & - & - \\
\hline Company 2 & $\mathrm{X}$ & $\mathrm{X}$ & $\mathrm{X}$ & $\mathrm{X}$ & - & - & - & - \\
\hline Company 3 & $\mathrm{X}$ & $\mathrm{X}$ & $\mathrm{X}$ & $\mathrm{X}$ & - & $\mathrm{X}$ & - & - \\
\hline Company 4 & $\mathrm{X}$ & $\mathrm{X}$ & $\mathrm{X}$ & $\mathrm{X}$ & - & $\mathrm{X}$ & - & $\mathrm{X}$ \\
\hline
\end{tabular}


suggested purchasing the product in large packs and the subsequent distribution in smaller amounts gradually. The decision to implement this idea generated savings of $400 \mathrm{~kg}$ with packaging disposal for the company:

The staff line used a chemical that was a tiny package so they gave the idea of buying a larger pack and go segregating the product gradually. Instead of people generate waste $500 \mathrm{Kg}$, we started to generate $100 \mathrm{~kg}$ (speaking of Management 2, 2016).

Company 3 decided to implement a long-term plan to end any kind of deforestation in its soy production chain on the basis of the demand of their European customers, mainly requiring the certification of grain purchasing and also because of the goals of large enterprise customers seeking zero deforestation. Civil associations also exerted pressure to conduct an increasingly sustainable Company 3 :

Our customers were also doing this kind of commitment, customers who use our products worldwide. We also needed to collaborate with the goals of these clients. Moreover, there is strong external pressure from civil society seeking zero deforestation [...] we have many customers who demand from us soy sustainability, major customers such as Unilever, Danone and BRF and we try to meet this kind of demand also they are important stakeholders for our business in Brazil. In addition, also have external customers, mainly in Europe that demand of people also initiatives and sustainable positions. Moreover, certification process which is a demand from Europe who want a guarantee that our soy complies with indicators that are even above the law (speaking of Management 3, 2016).

Company 4 has a virtual platform with global access (i.e. all employees can access this platform called "Voice Manifest"). It is through this platform that employees can suggest improvements to existing projects or suggest entirely new projects.

This platform had a positive impact in a project coordinated by Management 4. A person on the platform "Voice Manifest" had criticized the selective collection project; through the comment, the group responsible for implementing it developed improvement actions in the project. The actions included the redesign of waste disposal sites, e-mails explaining about what was or was not recyclable and an explanation the sorting of waste for cleaning staff:

One of the people of the divisions suggested that we were not doing here in the office effective communication of the issue of selective collection, which was messy and they did not know where they were going the materials. So it was done all a communication plan, not only e-mail communication, but reimagine the places where are the bins, put what's what will not, had an entire communication plan with the cleaning staff to do this (separation the garbage), this was one of the points that came to Brazil (speaking of Management 4, 2016).

Exchanging information with competitors is another action of resilience, particularly for getting information about incidents caused by others companies to prevent them from happening. Companies 1, 2 and 4 have acquired this information through benchmarking with other people from other companies, industry events or by participating in forums and associations; even the media is used to hearing about this kind of information. These benchmarking strategies made by companies are a favourable organizational eco-capability (Gabler et al., 2015).

Involvement with universities and research institutes is configured as information sources in Companies 2, 3 and 4 to discover new industrial processes to increase efficiency and reduce the natural impact. Maintaining close relationships with clients is an important information source for Company 3 because through this relationship, it can keep up with the demands of sustainability required while improving their value chain.

All these sources of information contributed to how companies decide on issues for improvement regarding sustainability. The industries have implemented environmental committees, adopted long-term plans and improved operations, which demonstrate the 


\section{IJCCSM 9,5}

\section{4}

Table V.

Organizational capabilities and resilience actions from companies

capability of incorporating knowledge from the stakeholders into processes and strategies, thus innovating them for sustainability (Ayuso et al., 2006) (Table V).

\subsection{Human capabilities}

To develop cohesion among members of the organization is a resilient action, because of the sharing of values and generation of commitment (McCann et al., 2009). The leaders' behaviours embody being subjective and provides organizational members an example of how to act and think within the organizations (Schneider et al., 1994). Managers 1, 2 and 4 reported the behaviour of the leaders to be that of role models with organizational thinking. Company 4 specifically has shown a strong organizational culture with values and sustainable principles rooted in the daily lives of all employees and encourages employees to always look for ways to improve the sustainability in the company. Features such as commitment of managers, directors and the president towards environmental issues and shared sense among members about the benefits of sustainable activities are part of building sustainable human resource capabilities (Schneider et al., 1994; Gabler et al., 2015).

In the dialogues with Managers 1 and 2, the importance of leadership involvement with sustainable issues became clear. Company 1 is a family business, and despite being large (about 7,000 employees), the owners are always present in the company. Manager 1 reported that they have grown within the organization, and they know even the technical ways to impress the leadership:

Our directors and the owners are very involved in environmental issues so that just gives you discuss with him technically. We had a problem at the station, the owner was passing by and said, "do this and that." They grew up in the business and know everything, they are very involved (speaking of Management 1, 2016).

Another example of leadership is in the daily intermediate team political talk about the environment and safety. The environmental team is responsible for developing a monthly booklet and a section is read daily by leaders along with their subordinates. This booklet has a different theme each day about work safety and environment:

We have some tools, the simplest calls DDSMA (daily dialogue safety and environment). Every month end, we have prepared a booklet, every day with a different theme both work safety as environment and every day before starting the work shift is the first, second or third shift. The leader of the area, the people of the area, they see this DDSMA so that they all have an interest, something 15 or 10 minutes for everyone to have a daily training of safety and environment, is the same dialogue (speaking of Management 2, 2016).

Company 3 has sustainability well institutionalized. This shows that the values of sustainability have been adhered to by the company's management, as seen in this transcript:

Shared sense among members about the benefits of sustainability and

Provision of information to employees about the implemented sustainable programmes

Participatory management and incorporate new

Companies knowledge acquired on shared goals and action plans

Benchmarking of internal strategies with competitors

Alliances and partnerships

\begin{tabular}{lll}
\hline Company 1 & $\mathrm{X}$ & $\mathrm{X}$ \\
Company 2 & $\mathrm{X}$ & $\mathrm{X}$ \\
Company 3 & $\mathrm{X}$ & $\mathrm{X}$ \\
Company 4 & $\mathrm{X}$ & $\mathrm{X}$ \\
\hline
\end{tabular}


We have a corporate person responsible for the environment, in all our factories we also have a person responsible for the environment. These people in the factory do not report to me, they report to this corporate environment manager. We have other people responsible for sustainability with a different scope, they report to another manager. There is also the sustainability manager who is corporate who at some point works together with other sustainability people from other businesses and at some time totally separate (speaking of Management 3, 2016).

The culture of Company 4 involved the role of inculcation sustainability behaviour in its employees. According to Manager 4, sustainability is present in the company's history, and the first president of the company reinforced the idea to care about not only what happened at the factory gates, it is also necessary to think beyond. His successor declared that a company could not survive in a desert of resources and people. The current president reinforced the issue of a double project involving social and environmental aspects in all organizational processes and throughout the value chain.

When an employee enters Company 4, it goes through an integration and process of immersion in the culture and the main points of sustainability valued by the company. Culture is considered an internal north for developers to consider how continuously to improve internal sustainability, as the transcript of Manager 4 shows: "we believe that (sustainability) is part of day to day, much more than conceptually, we believe in sustainability throughout our value chain, in all the processes that we do" (Table VI).

\section{Conclusions}

The study aimed to identify which dynamic capabilities foster organizational resilience towards sustainability. The first step was the description of the practices that represent resilience for sustainability as the literature indicated (Fiksel, 2003). They are adaptability to stimulate organizational learning/multistrategy adaptability to organizational learning; eco-efficiency on natural resources used; and organizational cohesion represented by common shared values. After field research with four case studies, three managerial dimensions were found for three dynamic capabilities that could foster an organization into sustainable resilience. In other words, resilience was the motor to enhance the capability of sustainable initiatives, or eco-capabilities.

As shown in Table VII, the dimensions are human, organizational and technological capabilities. The first dimension relates to leaders' behaviours and the workplace culture according to Freitas (1991), Schneider et al. (1994), Gabler et al. (2015) and the cohesion conception of Fiksel (2003). The second is about organizational capabilities; it deals with

\begin{tabular}{|c|c|c|}
\hline presid & conmental issues & Organizational climate \\
\hline Companies & Behaviour of leaders & Values and beliefs sustained by the organization \\
\hline
\end{tabular}

\begin{tabular}{lllr}
\hline Company 1 & $\mathrm{X}$ & $\mathrm{X}$ & Table VI. \\
Company 2 & $\mathrm{X}$ & $\mathrm{X}$ & Human capabilities \\
Company 3 & - & $\mathrm{X}$ & and resilience actions \\
Company 4 & $\mathrm{X}$ & $\mathrm{X}$ & from companies \\
\hline
\end{tabular}

Resilience capabilities for sustainability

Human capabilities $\quad$ Behaviour of leaders and shared culture among members

Organizational capabilities Benchmarking and communication between areas and distinct hierarchies

Technological capabilities

Long-term plans, regular meetings and eco-efficient actions

Sustainability as an ecocapability

595 


\section{IJCCSM 9,5}

communication among hierarchy and the process that facilitates organizational change. That dimension agrees with previous work by Galappaththi and Berkes (2015) and the proposal dimension of adaptability of Fiksel (2003). The third dimension was detected by the answers of companies related to planning and problem-solving processes and products. It has been mentioned by O'Connell and Hou (2015) and Bettini et al. (2015) and it is shown in the Fiksel (2003) dimension of diversity of strategy.

In this sense, it is possible to consider that the qualitative data that the interviewed companies provided could refine the Fiksel model into an updated concept which would be the key managerial dynamic capability that fosters organizational resilience towards sustainability. They are human, organizational and technological capabilities.

The case studies could provide new understandings to Fiksel model, helping to not only understand the aspects related to organizational resilience but also address the managerial dimensions that foster the resilience as a dynamic capability that can generate organizational sustainability. Being resilient cannot be in perpetual maintenance; it is necessary that companies develop a way to dynamically pursue resilience as a pattern of internal behaviour. For that, our cases could contribute to Fiksel's theory about the components of organizational resilience, expanding the understandings of how to maintain the resilient behaviour over time.

The theoretical implications of the case studies over the Fiksel model rely on how to promote resilience on its different aspects that compose the resilient behaviour over time. Besides highlighting the model that has the main objective to help organizations seek resilience, it also gives practical answers on how to develop the resilient aspects and maintain them inside a company.

The study has two practical implications for companies to continue working for sustainability. The first practical implication is the need to implement processes aimed at the exchange of information both internally and externally to the organization. It has been seen in the talks with managers that creating ways to listen to employee suggestions could make important resource-saving discoveries and reduce waste. A second practical implication is the need to work with the human side of the organization; sustainability needs to be part of the workers' daily lives, becoming common to reflect on how to improve the sustainability of the processes of which they are responsible. To achieve this goal, companies need to work the pillar of cohesion resilience, emphasizing the behaviour of leaders (role models) and organizational culture.

The study has limitations such as a small sample of companies. It is suggested that future studies can verify the relationship between the procedural and human practices found within the generation of dynamic capabilities for sustainability through quantitative studies in industrial companies.

\section{References}

Aguado, S., Alvarez, R. and Domingo, R. (2013), "Model of efficient and sustainable improvements in a lean production system through processes of environmental innovation", Journal of Cleaner Production, Vol. 47, pp. 141-148.

Aldunce, P., Beilin, R., Howden, M. and Handmer, J. (2015), "Resilience for disaster risk management in a changing climate: practitioners' frames and practices", Global Environmental Change, Vol. 30, pp. 1-11.

Annarelli, A. and Nonino, F. (2016), "Strategic and operational management of organizational resilience: current state of research and future directions", Omega, Vol. 62, pp. 1-18.

Augier, M. and Teece, D.J. (2008), "Strategy as evolution with design: the foundations of dynamic capabilities and the role of managers in the economic system", Organization Studies, Vol. 29 Nos 8/9, pp. 1187-1208. 
Augier, M. and Teece, D.J. (2009), "Dynamic capabilities and the role of managers in business strategy and economic performance”, Organization Science, Vol. 20 No. 2, pp. 410-421.

Ayuso, S., Rodríguez, M.A. and Enric Ricart, J. (2006), "Using stakeholder dialogue as a source for new ideas: a dynamic capability underlying sustainable innovation", Corporate Governance: The International Journal of Business in Society, Vol. 6 No. 4, pp. 475-490.

Bardin, L. (2011), “Análise de conteúdo”, Edições, Lisboa Vol. 70.

Barreto, I. (2010), "Dynamic capabilities: a review of past research and an agenda for the future", Journal of Management, Vol. 36 No. 1, pp. 256-280.

Berkes, F. (2009), "Evolution of co-management: role of knowledge generation, bridging organizations and social learning", Journal of Environmental Management, Vol. 90 No. 5, pp. 1692-1702.

Bettini, Y., Brown, R.R. and Haan, F.J. (2015), "Exploring institutional adaptive capacity in practice: examining water governance adaptation in Australia”, Ecology and Society, Vol. 20 No. 1, p. 47.

Boni, V. and Quaresma, S.J. (2005), "Aprendendo a entrevistar: como fazer entrevistas em ciências sociais”, Em Tese, Vol. 2 No. 1, pp. 68-80.

Campos, K.P. (2015), "Dimensions of business resilience in the context of post-disaster recovery in Davao City, Philippines", Review of Integrative Business \& Economics Research, Vol. 5 No. 1, pp. 168-198.

Chornomaz, V., Gawron, M., Górska, D., Iurkova, M., Jędrzejczak, M., Lewandowska, U. and Tarnas, A. (2016), "Eco-efficiency as a problem in managing contemporary enterprises", Systemy Wspomagania w Inżynierii Produkcji, Vol. 3 No. 15, pp. 52-58.

Chousa, J.P. and Castro, N.R. (2011), "Responsabilidade social empresarial e resiliência”, Revista galega de Economia: Publicación Interdisciplinar da Facultade de Ciencias Económicas e Empresariais, Vol. 20 No. 2, pp. 123-154.

Costanza, R. and Patten, B.C. (1995), "Defining and predicting sustainability", Ecological Economics, Vol. 15 No. 3, pp. 193-196.

Crichton, M.T., Ramsay, C.G. and Kelly, T. (2009), "Enhancing organizational resilience through emergency planning: learnings from cross-sectoral lessons", Journal of Contingencies and Crisis Management, Vol. 17 No. 1, pp. 24-37.

Derissen, S., Quaas, M.F. and Baumgärtner, S. (2011), "The relationship between resilience and sustainability of ecological-economic systems", Ecological Economics, Vol. 70 No. 6, pp. 1121-1128.

Eisenhardt, K.M. (1989), "Building theories from case study research", Academy of Management Review, Vol. 14 No. 4, pp. 532-550.

Eisenhardt, K.M. and Martin, J.A. (2000), "Dynamic capabilities: what are they?”, Strategic Management Journal, Vol. 21 Nos 10/11, pp. 1105-1121.

Fiksel, J. (2003), "Designing resilient, sustainable systems", Environmental Science \& Technology, Vol. 37 No. 23, pp. 5330-5339.

Fiksel, J. (2006), "Sustainability and resilience: toward a systems approach", Sustainability: Science, Practice, \& Policy, Vol. 2 No. 2.

Fiksel, J., Bruins, R., Gatchett, A., Gilliland, A. and Ten Brink, M. (2014), "The triple value model: a systems approach to sustainable solutions", Clean Technologies and Environmental Policy, Vol. 16 No. 4, pp. 691-702.

Freitas, M.E.D. (1991), "Cultura organizacional grandes temas em debate”, Revista de Administraçao de empresas, Vol. 31 No. 3, pp. 73-82.

Gabler, C.B., Richey, R.G. and Rapp, A. (2015), "Developing an eco-capability through environmental orientation and organizational innovativeness", Industrial Marketing Management, Vol. 45, pp. 151-161.

Galappaththi, E.K. and Berkes, F. (2015), "Can co-management emerge spontaneously? Collaborative management in Sri Lankan shrimp aquaculture”, Marine Policy, Vol. 60, pp. 1-8.

Sustainability as an ecocapability 


\section{IJCCSM 9,5}

Galpin, T., Whittington, J.L. and Bell, G. (2013), "Is your sustainability strategy sustainable? Creating a culture of sustainability”, Corporate Governance, Vol. 15 No. 1, pp. 1-17.

Gioia, D.A., Corley, K.G. and Hamilton, A.L. (2013), "Seeking qualitative rigor in inductive research notes on the Gioia methodology", Organizational Research Methods, Vol. 16 No. 1, pp. 15-31.

Holling, C.S. (1973), "Resilience and stability of ecological systems", Annual Review of Ecology and Systematics, Vol. 4, pp. 1-23.

Juechter, W.M., Fisher, C. and Alford, R.J. (1998), "Five conditions for high-performance cultures", Training and Development-Alexandria-American Society for Training and Development, Vol. 52, pp. 63-68.

Korhonen, J. and Seager, T.P. (2008), "Beyond eco-efficiency: a resilience perspective”, Business Strategy and the Environment, Vol. 17 No. 7, pp. 411-419.

Langley, A. (1999), "Strategies for theorizing from process data", Academy of Management Review, Vol. 24 No. 4, pp. 691-710.

Lengnick-Hall, C.A. and Beck, T.E. (2005), "Adaptive fit versus robust transformation: how organizations respond to environmental change", Journal of Management, Vol. 31 No. 5, pp. 738-757.

Lew, A.A., Ng, P.T., Ni, C.C. and Wu, T.C. (2016), "Community sustainability and resilience: similarities, differences and indicators”, Tourism Geographies, Vol. 18 No. 1, pp. 18-27.

Liboni, L.B., Caldana, A.C.F., Alves, M.F.R. and Cezarino, L.O. (2015), "Sustainability as a dynamic capacity: evidence in a Brazilian sugarcane energy company", 31st European Group for Organizational Studies (EGOS) Colloquium, 2015.

Liboni, L.B., Chiappetta, J.C.J., Jabbour, A. and Kannan, D. (2016), "Sustainability as a dynamic organizational capability: a systematic review and a future agenda toward a sustainable transition", Journal of Cleaner Production, Vol. 142, pp. 308-322.

Linnenluecke, M. and Griffiths, A. (2010), "Beyond adaptation: resilience for business in light of climate change and weather extremes", Business \& Society, Vol. 49 No. 3, pp. 477-511.

McCann, J., Selsky, J. and Lee, J. (2009), "Building agility, resilience and performance in turbulent environments", People and Strategy, Vol. 32 No. 3, p. 44.

Mari, S.I., Lee, Y.H. and Memon, M.S. (2014), "Sustainable and resilient supply chain network design under disruption risks", Sustainability, Vol. 6 No. 10, pp. 6666-6686.

Mirfenderesk, H. and Corkill, D. (2009), "The need for adaptive strategic planning: sustainable management of risks associated with climate change”, Vol. 1 No. 2, pp. 146-159.

Munck, L. and Borim-de-Souza, R. (2009), "Responsabilidade social empresarial e sustentabilidade organizacional: a hierarquização de caminhos estratégicos para o desenvolvimento sustentável”, REBRAE-Revista Brasileira de Estratégia, Vol. 2 No. 2, pp. 185-202.

O'Connell, S. and Hou, D. (2015), "Resilience: a new consideration for environmental remediation in an era of climate change", Remediation Journal, Vol. 26 No. 1, pp. 57-67.

Ortiz-de-Mandojana, N. and Bansal, P. (2016), "The long-term benefits of organizational resilience through sustainable business practices”, Strategic Management Journal, Vol. 37, pp. 1615-1631.

Plummer, R. and Armitage, D. (2007), “A resilience-based framework for evaluating adaptive comanagement: linking ecology, economics and society in a complex world”, Ecological Economics, Vol. 61 No. 1, pp. $62-74$.

Puente-Rodríguez, D., van Slobbe, E., Al, I.A. and Lindenbergh, D.D. (2016), "Knowledge co-production in practice: enabling environmental management systems for ports through participatory research in the Dutch Wadden Sea”, Environmental Science \& Policy, Vol. 55, pp. 456-466.

Redman, C. (2014), "Should sustainability and resilience be combined or remain distinct pursuits?", Ecology and Society, Vol. 19 No. 2. 
Roper, J. (2012), "Environmental risk, sustainability discourses, and public relations", Public Relations Inquiry, Vol. 1 No. 1, pp. 69-87.

Schneider, B., Gunnarson, S.K. and Niles-Jolly, K. (1994), "Creating the climate and culture of success", Organizational Dynamics, Vol. 23 No. 1, pp. 17-29.

Schrettle, S., Hinz, A., Scherrer-Rathje, M. and Friedli, T. (2014), "Turning sustainability into action: explaining firms' sustainability efforts and their impact on firm performance", International Journal of Production Economics, Vol. 147, pp. 73-84.

Strauss, A. and Corbin, J. (1998), Basics of Qualitative Research: Techniques and Procedures for

Sustainability as an ecocapability Developing Grounded Theory, Sage Publications.

Su, H.C., Linderman, K., Schroeder, R.G. and Van de Ven, A.H. (2014), "A comparative case study of sustaining quality as a competitive advantage", Journal of Operations Management, Vol. 32 No. 7, pp. 429-445.

Teece, D.J. (2007), "Explicating dynamic capabilities: the nature and microfoundations of (sustainable) enterprise performance", Strategic Management Journal, Vol. 28 No. 13, pp. 1319-1350.

Teece, D. and Pisano, G. (1994), "The dynamic capabilities of firms: an introduction", Industrial and Corporate Change, Vol. 3 No. 3, pp. 537-556.

Teece, D.J., Pisano, G. and Shuen, A. (1997), "Dynamic capabilities and strategic management", Strategic Management Journal, pp. 509-533.

Townshend, I., Awosoga, O., Kulig, J. and Fan, H. (2015), "Social cohesion and resilience across communities that have experienced a disaster", Natural Hazards, Vol. 76 No. 2, pp. 913-938.

Winnard, J., Adcroft, A., Lee, J. and Skipp, D. (2014), "Surviving or flourishing? Integrating business resilience and sustainability", Journal of Strategy and Management, Vol. 7 No. 3, pp. 303-315.

$\mathrm{Xu}, \mathrm{L}$., Marinova, D. and Guo, X. (2015), "Resilience thinking: a renewed system approach for sustainability science", Sustainability Science, Vol. 10 No. 1, pp. 123-138.

Yin, R.K. (2013), Case Study Research: Design and Methods, Sage publications.

Zollo, M. and Winter, S.G. (2002), "Deliberate learning and the evolution of dynamic capabilities", Organization Science, Vol. 13 No. 3, pp. 339-351.

\section{Further reading}

Hollnagel, E. (2011), "RAG-The resilience analysis grid", in Hollnagel, E., Pariès, J., Woods, D.D. and Wreathall, J. (Eds), Resilience Engineering in Practice: A Guidebook, Ashgate.

\section{Corresponding author}

Lara Bartocci Liboni can be contacted at: lara.liboni@gmail.com

For instructions on how to order reprints of this article, please visit our website: 